\title{
Effect of 8-hydroxyquinoline and derivatives on human neuroblastoma SH-SY5Y cells under high glucose
}

\author{
Wilasinee Suwanjang ${ }^{1}$, Supaluk Prachayasittikul ${ }^{2}$, Virapong Prachayasittikul ${ }^{\text {corresp. }} 3$ \\ ${ }^{1}$ Center for Research and Innovation, Faculty of Medical Technology, Mahidol University, Mahidol University, Bangkok, Thailand \\ 2 Center of Data Mining and Biomedical Informatics, Faculty of Medical Technology, Mahidol University, Bangkok, Thailand \\ 3 Department of Clinical Microbiology and Applied Technology, Faculty of Medical Technology, Mahidol University, Bangkok, Thailand \\ Corresponding Author: Virapong Prachayasittikul \\ Email address: virapong.pra@mahidol.ac.th
}

8-Hydroxyquinoline and derivatives exhibit multifunctional properties, including antioxidant, antineurodegenerative, anticancer, anti-inflammatory and antidiabetic activities. In biological systems, elevation of intracellular calcium can cause calpain activation, leading to cell death. Here, the effect of 8-hydroxyquinoline and derivatives (5chloro-7-iodo-8-hydroxyquinoline or clioquinol and 8-hydroxy-5-nitroquinoline or nitroxoline) on calpain-dependent (calpain-calpastatin) pathways in human neuroblastoma (SH-SY5Y) cells was investigated. 8-Hydroxyquinoline and derivatives ameliorated high glucose toxicity in SH-SY5Y cells. The investigated compounds, particularly clioquinol, attenuated the increased expression of calpain, even under high-glucose conditions. 8Hydroxyquinoline and derivatives thus adversely affected the promotion of neuronal cell death by high glucose via the calpain-calpastatin signaling pathways. These findings support the beneficial effects of 8-hydroxyquinolines for further therapeutic development. 
1 2

3

4

5

6

\section{Effect of 8-hydroxyquinoline and derivatives on human neuroblastoma SH-SY5Y cells under high glucose}

\author{
7 Bangkok, 10700, Thailand \\ $8 \quad{ }^{2}$ Center of Data Mining and Biomedical Informatics, Faculty of Medical Technology, Mahidol \\ 9 University, Bangkok, 10700, Thailand \\ Wilasinee Suwanjang ${ }^{1}$, Supaluk Prachayasittikul ${ }^{2}$, Virapong Prachayasittikul ${ }^{3, *}$ \\ ${ }^{3}$ Department of Clinical Microbiology and Applied Technology, Faculty of Medical Technology, \\ Mahidol University, Bangkok, 10700, Thailand
}

* Corresponding author: Virapong Prachayasittikul, Ph.D

Professor, Faculty of Medical Technology, Mahidol University, Bangkok 10700, Thailand

E-mail: virapong.pra@mahidol.ac.th, Phone: +66 2441 4371-5; Fax: +66 24414380

6


ABSTRACT

36

8-Hydroxyquinoline and derivatives exhibit multifunctional properties, including antioxidant, antineurodegenerative, anticancer, anti-inflammatory and antidiabetic activities. In biological systems, elevation of intracellular calcium can cause calpain activation, leading to cell death. Here, the effect of 8-hydroxyquinoline and derivatives (5-chloro-7-iodo-8-hydroxyquinoline or clioquinol and 8-hydroxy-5-nitroquinoline or nitroxoline) on calpain-dependent (calpaincalpastatin) pathways in human neuroblastoma (SH-SY5Y) cells was investigated. 8Hydroxyquinoline and derivatives ameliorated high glucose toxicity in SH-SY5Y cells. The investigated compounds, particularly clioquinol, attenuated the increased expression of calpain, even under high-glucose conditions. 8-Hydroxyquinoline and derivatives thus adversely affected the promotion of neuronal cell death by high glucose via the calpain-calpastatin signaling pathways. These findings support the beneficial effects of 8-hydroxyquinolines for further 48 therapeutic development.

49

50 

and tremendously impacts human health worldwide. Hyperglycemia contributes to the long-term diabetic complications i.e., retinopathy, nephropathy and neuropathy (Aronsonons, 2008). Epidemiological evidence suggests that patients with DM have a significantly high risk (50100\%) of developing Alzheimer's disease (Biessels et al., 2006). Diabetic patients exhibit cognitive impairment including damaged verbal memory, diminished mental speed and mental Alzheimer's disease, and many Alzheimer's patients exhibit impaired fasting glucose (Janson et al., 2004).

Neuronal cells cannot protect themselves from the harmful effects of excess glucose. The most likely mechanism for glucose toxicity is the generation of excess reactive oxygen species (ROS) via multiple mitochondrial and non-mitochondrial pathways (Newsholme et al., 2007). In addition to ROS production, high glucose levels trigger multiple biochemical pathways and toxicity, which contribute to damage to DNA, lipid, proteins and subsequent neurotoxicity (Li et al., 2014). However, the mechanisms underlying the association of high glucose with neurodegeneration remain to be fully elucidated.

Calpain is an intracellular $\mathrm{Ca}^{2+}$-dependent cysteine protease that is activated by increased intracellular $\mathrm{Ca}^{2+}$. Calpain plays a vital role in glucose metabolism, cytoskeletal remodeling for cell cycle regulation and apoptosis, probably as a consequence of a loss of $\mathrm{Ca}^{2+}$ homeostasis (Vosler et al., 2008). Calpain cleaves and inactivates pro-caspase 9, pro-caspase 3 (Chua et al., 2000) and APAF-1 (Lankiewicz et al., 2000). Calpastatin is a specific endogenous calpain inhibitor (Croall and Ersfeld, 2007). Calpain activity underlies the pathophysiology of several neurodegenerative diseases such as ischemia and epilepsy (Vosler et al., 2008), and 
94 95 96

overexpression of calpastatin improves ischemia and reperfusion (Maekawa et al., 2003). Interestingly, the increase in calpain expression has been related to Bax, caspase-12, caspase-9 and caspase-3 in dopaminergic neurons (Das et al., 2006; McGinnis et al., 1998). The relative levels of calpain and dopamine in neuron involve the process of neurodegeneration such as Parkinson's and Alzheimer's diseases (Chen et al., 2011; Carragher et al., 2006).

The biometal chelators (Prachayasittikul et al., 2013) 8-hydroxyquinoline, 5-chloro-7-iodo-8hydroxyquinoline (clioquinol) and 5-nitro-8-hydroxyquinoline (nitroxoline), shown in (Fig. 1A), have been proposed as a potential therapeutic strategy for the treatment of Alzheimer's disease (Bush, 2008). Clioquinol was identified as a prototype metal-protein-attenuating compound (Barnham et al., 2004a). The effect of clioquinol is related to its lipophilicity and ability to form relatively stable complexes with zinc (II) and copper (II) ions. Several reports have provided evidence that long-term pretreatment with clioquinol reduces the susceptibility of substantia nigra neurons to neurotoxin (Kaur et al., 2003). These compounds (Fig. 1A) are structurally related and bear 8-hydroxyquinoline as a core structure. Clioquinol is a halogenated derivative, and nitroxoline is the nitro derivative of 8-hydroxyquinoline. 8-Hydroxyquinoline and derivatives are bioavailable antioxidants that can cross the blood-brain barrier and inhibit metalhydrogen peroxide production (Barnham et al., 2004b).

Herein, the protective effects of 8-hydroxyquinoline, clioquinol and nitroxoline on human neuroblastoma cells under high glucose were investigated.

\section{MATERIALS AND METHODS}

\section{Chemicals and reagents}

Minimum essential medium (MEM), Ham’s F-12 medium, fetal bovine serum (FBS), penicillin and streptomycin were purchased from Gibco BRL (Gaithersburg MD, USA). Mouse monoclonal anti-actin (catalog number 3700), rabbit polyclonal anti-calpain (catalog number 2539), anti-calpastatin (catalog number 4146) and horseradish peroxidase-conjugated goat antimouse IgG and anti-rabbit IgG antibody were supplied by cell signaling (Beverly, MA, USA). Enhanced chemiluminescence (ECL) plus western blotting reagent was purchased from Amersham Biosciences (Piscataway, NJ, USA). The human dopaminergic neuroblastoma (SHSY5Y) cell line was obtained from American Type Culture Collection (Manassas, VA, USA). 
125 SH-SY5Y cells are a thrice cloned subline of bone marrow biopsy-derived line SK-N-SH. SH-

126 SY5Y cell has dopamine- $\beta$-hydroxylase activity and express tyrosine hydroxylase. 8-

127 Hydroxyquinoline (99\%), clioquinol ( $\geq 95 \%)$, and nitroxoline (96\%) were purchased from

128 Sigma-Aldrich (St Louis, MO, USA).

129

130

Cell cultivation

131 SH-SY5Y cells (passage number less than 25) were cultured in 75- $\mathrm{cm}^{3}$ flasks in MEM-F12

132 supplemented with $10 \%$ heat-inactivated FBS and $100 \mathrm{U} / \mathrm{mL}$ penicillin/streptomycin. Cells were

133 maintained at $37^{\circ} \mathrm{C}$ in an atmosphere of $5 \% \mathrm{CO}_{2}$ and $95 \%$ humidified air incubator, and were

134 feed with medium every other day. To perform experiments, cells were seeded in 96-well and 6-

135 well plates and grown to $70-80 \%$ confluence. Before the start of treatment, the medium was

136 replaced with MEM-F12 containing 1\% (v/v) FBS, as previously described (Dayem et al., 2014;

137 Kovalevich et al., 2013). It has been shown that cell incubation with D-glucose for $24 \mathrm{hr}$

138 significantly induced cell apoptosis via the activation of c-Jun N-terminal protein kinase (JNK)

139 and p-38 mitogen-activated protein kinase (MAPK) (Chen et al., 2013 and Ho et al., 2000). In

140 case of glucose-treated cells for $2 \mathrm{hr}$, the cells had significantly higher level of ROS

141 accumulation and promoted apoptotic cell death (Wu et al., 2004). Up to date, the mechanism of

142 high glucose contributing to degeneration in neuronal cells remains poorly understood. To

143 investigate the mechanism of high glucose level involved in neuronal cells death, in this study,

144 the cells were treated with D-glucose or D-mannitol at various concentrations $(5.5,30,60$ and

$145120 \mathrm{mM}$ ) for 2 or $24 \mathrm{hr}$, and compared the percentage of cell viability. In some experiments, 8-

146 hydroxyquinoline and derivatives were added to the medium for $2 \mathrm{hr}$ prior to an incubation with

147 D-glucose for $24 \mathrm{hr}$. Control untreated cells were incubated with the culture medium. Mannitol

148 was utilized as an osmotic control.

149

150

Cell viability assay

151 The 3-(4,5-dimethylthiazol-2-yl)-2,5-diphenyltetrazolium bromide (MTT) assay was used to 152 assess neuronal injury after treatment of SH-SY5Y cells with a drug. When MTT is taken up by 153 live cells, it is converted from yellow to dark blue formazan crystals by cellular dehydrogenase

154 (Stockert et al., 2012). MTT in $0.1 \mathrm{mM}$ phosphate buffered saline (PBS) was added to each well 155 and incubated at $37^{\circ} \mathrm{C}$ for $4 \mathrm{hr}$. The solution was discarded, and extraction buffer $(0.04 \mathrm{~N} \mathrm{HCl}$ in 
156 isopropanol) was added. The optimal densities were measured at a spectral wavelength of 570

$157 \mathrm{~nm}$ using a microtiter plate reader.

158

159

\section{Western immunoblotting}

Treated cells were harvested and lysed by adding lysis buffer and scraped off the plate. Cells were sonicated for $10 \mathrm{~s}$ and centrifuged for $15 \mathrm{~min}$ at $12,000 \mathrm{~g}$. The supernatants were collected

162

163

164

165

166

167

168

169

170

171

172

173

174

175

176

177

178

179

180

181

182

183

184

185

186 and separated by sodium dodecyl sulfate-polyacrylamide gel electrophoresis. The protein bands were transferred to nitrocellulose membranes and washed with Tris-buffered saline and Tween 20 (TBST) for $5 \mathrm{~min}$. The membranes were incubated in a blocking buffer (5\% non-fat dry milk in TBST), then washed with TBST and incubated in primary antibodies at $4^{\circ} \mathrm{C}$ overnight. After the incubation, the membranes were washed three times with TBST for $5 \mathrm{~min}$ and then incubated in HRP-conjugated secondary antibody for $1.5 \mathrm{hr}$, followed by washing three times for 5 min each time with TBST. The blots were developed with ECL Plus Western Blotting detection reagents.

\section{Immunocytochemical analysis}

SH-SY5Y cells were seeded on sterile glass coverslips at $37^{\circ} \mathrm{C}$ for $24 \mathrm{hr}$ and then exposed to D-glucose in the medium containing $1 \% \mathrm{FBS}$ for $24 \mathrm{hr}$; control cells were incubated with medium for $24 \mathrm{hr}$. The cells were incubated with MitoTracker ${ }^{\circledR}$ Red CMXRos for $30 \mathrm{~min}$. The medium was removed, and the cells were washed with ice-cold PBS. The cells were fixed with $4 \%$ paraformaldehyde in PBS for $30 \mathrm{~min}$ at $4^{\circ} \mathrm{C}$ and washed with PBS three times for 5 min each time. Cells were permeabilized with 1\% Triton X-100 in PBS for $10 \mathrm{~min}$ at room temperature and rinsed with PBS three times. Non-specific antibody binding sites were blocked by incubating the cells with $10 \%$ donkey serum in PBS containing $0.3 \%$ Triton X-100 and 1\% bovine serum albumin (BSA) for $10 \mathrm{~min}$ at room temperature. Cells were incubated with the primary antibody against calpain (1:1,000 in PBS containing 0.3\% Triton X-100 and 0.25\% BSA) overnight at $4^{\circ} \mathrm{C}$, followed by incubation with fluorescein isothiocyanate (FITC)-conjugated donkey antirabbit IgG (1:200 in PBS containing 0.3\% Triton X-100 and 0.25\% BSA) for $2 \mathrm{hr}$ at room temperature. The cells were washed three times with PBS, and stained slides were mounted using antifade reagent in glycerol buffer (Vector Laboratories, Burlingame, USA) and visualized by fluorescence microscopy (Olympus, Tokyo, Japan). 
187

188

189

190

191

192

193

194

195

196

197

198

199

200

201

202

203

204

205

206

207

208

209

210

211

212

213

214

215

216

217

\section{Statistical analysis}

Data are expressed as mean \pm S.E.M. Significance was assessed by one-way analysis of variance (ANOVA) followed by a Tukey-Kramer test using SPSS 18 software package for Windows (Chicago, IL, USA). Probability $(P)$ values of less than 0.05 were considered statistically significant.

\section{RESULTS}

\section{Effect of high glucose on cell viability of SH-SY5Y cells}

The effect of high-glucose exposure on cell viability was investigated in SH-SY5Y cells using various concentrations of D-glucose and D-mannitol (an osmolality control) medium for 2 and $24 \mathrm{hr}$. Treatment with D-glucose for $2 \mathrm{hr}$ significantly decreased cell viability to $91.31 \pm 0.73 \%$ at $60 \mathrm{mM}(P<0.01)$ and to $82.59 \pm 2.59 \%$ at $120 \mathrm{mM}(P<0.001)$ compared with normal medium $(5.5 \mathrm{mM}$ glucose $)(\mathrm{F}$-value $=30.779)$ whereas treatment with D-glucose for 24 hr significantly decreased cell viability to $89.10 \pm 3.23 \%$ at $30 \mathrm{mM}(P<0.05)$, to $78.48 \pm 1.16 \%$ at $60 \mathrm{mM}(P<0.001)$, and to $73.97 \underline{2.31 \%}$ at $120 \mathrm{mM}(P<0.001)($ F-value $=31.564)$ (Fig. 2A). To rule out an effect of osmotic stress on SH-SY5Y cells treated with high glucose, cells were incubated with D-mannitol under the same conditions for the indicated time. The differences in cell viability, between cells treated with D-glucose and with D-mannitol at 60 or $120 \mathrm{mM}$ for 24 hr were statistically significant. However, high glucose at 60 and $120 \mathrm{mM}$ induced neuronal cell death as a result of hyperglycemia and hyperosmolarity. A decrease in the cell viability of neuronal cells was noted when the cells were treated with high glucose for $2 \mathrm{hr}$. Increasing the ambient D-glucose concentration caused dose- and time-dependent decreases in cell viability. Thus, $120 \mathrm{mM}$ D-glucose was selected to treat neurons in this study because this concentration has been used in many studies of hyperglycemia in vitro (Haslinger et al., 2001; Li et al., 2003; Song et al., 2015).

\section{Effect of high glucose induced calpain and reduced calpastatin protein levels}

To determine if the increase in calcium-dependent pathways induced by high glucose treatment occurs via upregulation of calpain protein, SH-SY5Y cells were incubated with various glucose concentrations $(5.5-120 \mathrm{mM})$ for the indicated time, the cell lysate was collected, and 
218 calpain and calpastatin levels were determined by Western blot analysis. Treatment with 120

$219 \mathrm{mM}$ D-glucose for $2 \mathrm{hr}$ or $24 \mathrm{hr}$ significantly increased calpain levels by $129.69 \pm 8.30 \%(P<$

$2200.01)($ F-value $=7.031)$ and 134.44 $\pm 3.97 \%(P<0.001)($ F-value $=31.964)$ compared with

221 control cells at the same time points (Fig. 2B). These results demonstrate that high glucose

222 induced calpain expression.

223 Further investigation of calpastatin, a specific endogenous calpain inhibitor, was performed

224 by Western immunoblotting. Interestingly, exposure to $60 \mathrm{mM}$ D-glucose resulted in increased

225 calpastatin expression as early as $2 \mathrm{hr}(124.80+2.88 \%, P<0.01)(\mathrm{F}$-value $=9.010)$, whereas 120

$226 \mathrm{mM}$ D-glucose exposure for $24 \mathrm{hr}$ significantly decreased calpastatin protein levels to

$22775.07 \pm 4.35 \%(P<0.001)($ F-value $=11.909)$ compared with the control (Fig. 2B).

228 To demonstrate that the observed increase in calpain was related to cell death, an

229 immunofluorescent double-labeling experiment was performed using MitoTracker Red as the

230 mitochondrial marker. Control (5.5 mM D-glucose) cells exhibited weak immunostaining of

231 calpain. However, cells treated with $120 \mathrm{mM}$ D-glucose displayed a bright green speckled

232 appearance that became more intense by $24 \mathrm{hr}$ after glucose administration (Fig. 3). Thus,

233 exposure to high glucose resulted in an induction of calpain immunofluorescence staining in SH-

234 SY5Y cells.

235

236

Cytotoxicity of 8-hydroxyquinoline and derivatives

237 The cytotoxic effects of 8-hydroxyquinoline and derivatives on cultured cells were assessed

238 at different concentrations using the tetrazolium salt reduction (MTT) assay. No significant

239 cytotoxic effect of 8-hydroxyquinoline and derivatives were evident at $1 \mu \mathrm{M}$ in SH-SY5Y cells

240 (8-hydroxyquinoline: $93.52 \pm 8.15 \%(\mathrm{~F}$-value $=10.726)$; clioquinol: $100.8+4.73 \%(\mathrm{~F}$-value $=$

241 0.40); nitroxoline: 86.44 $+5.87 \%($ F-value $=78.113)$ ) as shown in (Fig. 1B). Cytotoxic effects of

$24210 \mu \mathrm{M} 8$-hydroxyquinoline $(68.67 \pm 6.37 \%)$ and nitroxoline $(39.17 \pm 2.18 \%)$ were observed after

243 treatment for $24 \mathrm{hr}$, and therefore $1 \mu \mathrm{M}$ was used in subsequent experiments.

Protective effect of 8-hydroxyquinoline and derivatives on high glucose-reduced cell viability

247 The effects of 8-hydroxyquinoline and derivatives were further investigated by monitoring 248 cell viability changes in response to high-glucose $(120 \mathrm{mM})$ treatment for $24 \mathrm{hr}$. Exposure to 1 
249

250

251

252

253

254

255

256

257

258

259

260

261

262

263

264

265

266

267

268

269

270

271

272

273

274

275

276

277

278

279

$\mu \mathrm{M}$ clioquinol $(93.35 \pm 0.89 \%, P<0.001)$ or nitroxoline $(95.72 \pm 0.92 \%, P<0.001)$ significantly increased cell viability compared with high glucose-treated cells $(73.97 \pm 2.31 \% P<0.01)$ (Fvalue $=24.262)($ Fig. $4 \mathrm{~A})$. However, pretreatment with $1 \mu \mathrm{M}$ 8-hydroxyquinoline also significantly increased cell viability to $86.89 \pm 3.06 \%$. The protective effect of the compounds in order of potency was nitroxoline $>$ clioquinol $>8$-hydroxyquinoline.

\section{Effect of 8-hydroxyquinoline and derivatives on high glucose-induced calpain-calpastatin alteration}

8-Hydroxyquinoline and derivatives have been reported to exert antidiabetic activity (Prachayasittikul et al., 2013). Calpains are important regulators of the cell cycle and apoptosis, and their activities are dependent on the concentration of calcium in cells. We previously demonstrated that dexamethasone induced neuronal cell death via a calpain-dependent pathway (Suwanjang et al., 2013). In the present study, the effect of 8-hydroxyquinoline and derivatives on high glucose-induced calpain activation was observed (Fig. 4 B). Treatment of SH-SY5Y cells with $120 \mathrm{mM}$ D-glucose for $24 \mathrm{hr}$ resulted in calpain expression. Pretreatment with $1 \mu \mathrm{M} 8$ hydroxyquinoline and derivatives significantly attenuated calpain expression (8hydroxyquinoline; 109.82 $\pm 5.28 \%(P<0.05)($ F-value $=11.489)$; clioquinol; $104.91 \pm 4.95 \%(P<$ 0.01) $($ F-value $=13.919)$; nitroxoline: $105.47 \pm 1.49 \%(P<0.01)$ compared with the high glucosetreated cells $(133.19 \pm 5.32 \%, P<0.001)(\mathrm{F}-\mathrm{value}=19.840)$. A greater protective effect was observed for clioquinol, as evidenced by lower calpain expression under high glucose treatment. However, the protective effect of nitroxoline was comparable to that of clioquinol. By contrast, 8-hydroxyquinoline and derivatives tended to increase the expression of the calpain inhibitor (calpastatin, Fig. 4 C) by high glucose (8-hydroxyquinoline: $90.13 \pm 4.93 \%($ F-value $=2.840)$; clioquinol: $88.77 \pm 3.88 \%($ F-value $=7.683)$; nitroxoline: $89.61 \pm 1.31 \%($ F-value $=6.570))$ compared with the high glucose-treated cells $(83.03 \pm 4.02 \%, P<0.05)$. Moreover, treatment with 8-hydroxyquinoline and derivatives had no significant effects on the expressions of calpain and calpastatin in untreated control cells. 
Hyperglycemia is considered a risk factor of neurodegenerative diseases (Kopf and Frolich,

282

283

284

285

286

287

288

289

290

291

292

293

294

295

296

297

298

299

300

301

302

303

304

305

306

307

308

309

310

2009). Impairments in signaling mechanisms contribute to increased neuronal cell death.

Numerous studies have focused on elucidating the mechanism by which high glucose toxicity enhances death mechanisms. The optimal concentration of glucose for neuronal survival is reportedly in the range of 25-30 mM. Here, cell viability under high-glucose exposure in human neuroblastoma SH-SY5Y cells was investigated. The mechanisms underlying hyperglycemia and hyperosmolarity have been studied extensively. During hyperglycemia, high levels of glucoseinduced oxidative stress can cause cellular damage. In addition, excess glucose leads to neurotoxicity via increased apoptosis and inhibition of proliferation. This may activate p38 kinase associated with apoptosis via protein kinase $\mathrm{C}$-dependent and -independent pathways (Igarashi et al., 1999). The results suggest that elevated glucose level initiates harmful mechanisms leading to neuronal cell degeneration (neuropathy). High glucose (120 mM) was reported to affect $\mathrm{Ca}^{2+}$ homeostasis (Kimura et al., 1998). It is also well established that high glucose $(120 \mathrm{mM})$ induced oxidative stress and promoted calcium influx in a variety of cell types including human monocytes (Wuensch et al., 2010) and cardiac cells (Kumar et al., 2012; Ozdermir et al., 2005; Cai et al.,2002).

Impairment of $\mathrm{Ca}^{2+}$ homeostasis is an important factor in the development of neuronal degeneration (Todorovic and Jevtovic-Todorovic, 2014). Under physiological conditions, calpain is localized in the cytosol and is in an inactive form in the absence of calcium. Calpain is activated by cytosolic $\mathrm{Ca}^{2+}$ overload. The dysregulation of intracellular calcium levels is an indicator of neuronal injury through the activation of several enzymes such as calpains and phospholipases as well as mitochondrial alterations (Araujo et al., 2004). The calpain system plays a major role in various cellular signaling processes, including signal transduction, cell adhesion and motility, cell growth, differentiation and cell death. Calpain activates both caspasedependent and caspase-independent pathways to promote apoptosis. In the apoptotic pathway, calpain cleaves apoptotic inducing factor, which activates DNA degradation (Baritaud et al., 2010). Thus, the activation of calpain may have an important role in many diseases such as retinal photoreceptor apoptosis (Mahajan et al., 2012) and ischemia (Rami, 2003). A high concentration of glucose also results in morphological alterations and cell death via processes related to the apoptotic pathway (Allen et al., 2005). Accumulation of oxidative stress is present 
311 in diabetes. Therefore, high glucose can induce cellular hypertrophy by excessive production of

312 ROS. Clinical studies also indicate that high glucose enhances the pathology of diabetes by

313 increasing oxidative stress (Trombetta et al., 2005). In general, ROS are recognized as a main

314 source of molecular damage in hyperglycemia (Piconi et al., 2006).

315 Calpain activity is inhibited by endogenous calcium-dependent interactions with calpastatin.

316 Calpastatin binds to the active site and inhibits calpain in the presence of calcium (Goll et al.,

317 2003). Specific calpain inhibitors reduce neuronal damage in a number of different systems. The

318 current findings demonstrate that high concentrations of glucose can lead to increased calcium

319 levels and enhance calpain protein expression in a dose- and time-dependent manner. Increased

320 calpain expression has been implicated in vascular inflammation and endothelial leakage in

321 diabetes (Scalia et al., 2007). In addition, calpain plays significant roles in apoptotic processes

322 (Raynaud and Marcilhac, 2006). However, the expression of proteins related to the specific

323 calpain inhibitor (calpastatin) was decreased in SH-SY5Y cells treated with high glucose

324 concentrations. Furthermore, previous studies have suggested that neuronal calpain activity

325 mediates the initiation and expression of methamphetamine- and dexamethasone-induced cell

326 death (Suwanjang et al., 2013; Suwanjang et al., 2012). Several mechanisms have been proposed

327 for the effects of calpain during cell death, including cleavage of pro-caspase 3 and degradation

328 of apoptotic proteins (Camins et al., 2006).

329 Several studies have revealed a functional association of 8-hydroxyquinoline and derivatives with cancer, inflammation, Alzheimer's and Parkinson's diseases (Mao and Schimmer, 2008).

331 Of the tested derivatives, clioquinol is a bioavailable ligand with moderate affinity for copper, zinc and iron. Clioquinol possesses relatively high lipophilicity and crosses the blood-brain barrier. Clioquinol has been observed in brain tissue and cerebrospinal fluid (Bondiolotti et al., 2007) and exhibits neuroprotective effects in MPTP mouse (Kaur et al., 2003) and Alzheimer's models (Suh et al., 2000). Nitroxoline, a nitro derivative of hydroxyquinoline, is used as an antibacterial drug in patients with urinary tract infections (Wagenlehner et al., 2014; Ghoneim et al., 2011). Recently, clioquinol and nitroxoline have been reported to exert anticancer activity against cholangiocarcinoma cells (Chan-On et al., 2015). Clinical trial data suggest that 8hydroxyquinoline and its derivatives may also have benefits in preventing the development and progression of neurodegeneration. Clioquinol protects against cell death in in vivo and in vitro models of Parkinson's disease (Wilkins et al., 2009). The induction of calpain in neuronal cells 
342 might be closely related to several toxicity mechanisms, including caspase- 3 activation

343 (Bastianetto et al., 2011) and oxidative stress (Suwanjang et al., 2013). 8-Hydroxyquinoline and

344 derivatives have been reported as potent antidiabetic agents (Prachayasittikul et al., 2013). The

345 present study demonstrates that treatment of SH-SY5Y cells with 8-hydroxyquinoline and

346 derivatives results in decreased calpain expression and reduced neuronal cell death after high

347 glucose toxicity. Conversely, high-glucose toxicity might be controlled by treatment with 8-

348 hydroxyquinoline and derivatives. Notably, the compounds reduced the expression of calpain in

349 the order clioquinol $\approx$ nitroxoline $>8$-hydroxyquinoline. It has been suggested that 8 -

350 hydroxyquinoline and derivatives, especially clioquinol prevent $\mathrm{Ca}^{2+}$ influx and calcium signal in 351 Alzheimer's (LeVine et al., 2009; Abramov et al., 2005; Lin et al., 2003; Cherny et al., 2001)

352 and Parkinson's diseases (Cacciatore et al., 2013). Furthermore, it is also reasonable that 8-

353 hydroxyquinoline and derivatives decrease calpain but increase calpastatin expressions via their

354 antioxidant activities and reduce intracellular calcium level in high glucose toxicity. In addition,

355 the decrease in calcium level may be enhanced by metal chelating property of 8-

356 hydroxyquinoline and derivatives (Prachayasittikul et al., 2013).

357

358

359

360

361

362

363

364

365

366

367

368

369

REFERENCES

370

371

Abramov, A.Y., Canevari, L., Dunchen, M.R., 2005. Amyloid $\beta$ peptides induce

372

This study reveals that 8-hydroxyquinoline and derivatives offer partial neuroprotection against high glucose toxicity and modulate the balance between calpain and calpastatin expressions. These findings provide a foundation for the further therapeutic development of 8hydroxyquinoline compounds.

\section{ACKNOWLEDGEMENTS}

We thank Ms.Chayanit Sirisuwat for collecting the samples. 
373

374

375

376

377

378

379

380

381

382

383

384

385

386

387

388

389

390

391

392

393

394

395

396

397

398

399

400

401

402

activation of NADPH oxidase. Journal of Neuroscience 24, 565-575.

Allen, D., Yaqoob, M., Harwood, S., 2005. Mechanisms of high glucose-induced apoptosis and its relationship to diabetic complications. Journal of Nutritional Biochemistry 16, 705713.

Araujo, I., Verdasca, M., Leal, E., 2004. Early calpain-mediated proteolysis following AMPA receptor activation compromises neuronal survival in cultured hippocampal neurons. Journal of Neurochemistry 91, 1322-1331.

Aronsonons, D., 2008. Hyperglycemia and the pathobiology of diabetic complication. Advances in Cardiology 45, 1-16.

Baritaud, M., Boujrad, H., Lorenzo, H.K., Krantic, S., Susin, S.a., 2010. Histone H2AX: the missing link in AIF-mediated caspase-independent programmed necrosis. Cell cycle 9, 31663173.

Barnham, K., Cheny, R., Cappai, R., 2004a. Metal protein attenuating componds (MPACs) for the treatment of Alzheimer's disease. Drug Design Reviews Online 1, 75-82.

Barnham, K., Haeffner, F., Ciccotosto, G., Curtain, C., Tew, D., Mavros, C., Beyreuther, K., Carrington, D., Cherny, R., Cappai, R., Bush, A., 2004b. Tyrosine gated electron transfer is key to the toxic mechanism of Alzheimer's disease beta-amyloid. FASEB Journal $18,1427-1429$.

Bastianetto, S., Krantic, S., Chabot, J., Quirion, R., 2011. Possible involvement of programmed cell death pathways in the neuro-protective action of polyphenols. Current Alzheimer Research 8, 445-451.

Biessels, G., Staekenborg, S., Brunner, E., Brayne, C., Scheltens, P., 2006. Risk of dementia in diabeties mellitus: a systematic review. The Lancet Neurology 5, 64-74.

Bondiolotti, G., Sala, M., Pollera, C., Gervasoni, M., Puricelli, M., Ponti, W., Bareggi, S., 2007. Pharmacokinetics and distribution of clioquinol in golgen hamsters. Journal of Pharmacy and Pharmacology 59, 387-393.

Bush, A., 2008. Drug development based on the metals hypothesis of Alzheimer's disease. Journal of Alzheimer's Disease 15, 223-240.

Cacciatore, I., Fornasari, E., Baldassarre, L., Cornacchia, C., Fulle, S., Filippo, E.S.D., Pietrangelo, T., Pinnen, F., 2013. A potent (R)-alpha-bis-lipoyl derivative containing 8- 
403

404

405

406

407

408

409

410

411

412

413

414

415

416

417

418

419

420

421

422

423

424

425

426

427

428

429

430

431

432

hydroxyquinoline scaffold: synthesis and biological evaluation of its neuroprotective capabilities in SH-SY5Y human neuroblastoma cells. Pharmaceuticals 6, 54-69.

Cai, L., Li, W., Wang, G., Guo, L., Jiang, Y., Kang, Y.J., 2002. Hyperglycemia-induced apoptosis in mouse myocardium: mitochondrial cytochrome $c$-mediated caspase-3 activation pathway. Diabetes 51, 1938-1948.

Camins, A., Verdaguer, E., Folch, J., Pallas, M., 2006. Involvement of calpain activation in neurodegenerative processes. CNS Drug Reviews 12, 135-148.

Carragher, N.O., 2006. Calpain inhibition: a therapeutic strategy targeting multiple disease states. Current Pharmaceurical Design 12, 615-638.

Chan-On, W., Huyen, NP., Songtawee, N., Suwanjang, W., Prachayasittikul, S., Prachayasittikul, V., 2015. Quinoline-based clioquinol and nitroxoline exhibit anticancer activity inducing FoxM1 inhibition in cholangiocarcinoma cells. Journal of Drug Design, Development and Therapy 9, 2033-2047.

Chen, J., Guo, Y., Chen, W., Chen, R., Liu, T., Chen, Z., Tan, S., 2013. High glucose induces apoptosis and suppresses proliferation of adult rat neural stem cells following in vitro ischemia. BMC Neuroscience 14, 24.

Chen, M., Nguyen, H.T., Sawmiller, D.R., 2011. What to look for beyond pathogenic factors in senile dementia? A functional deficiency of $\mathrm{Ca}^{2+}$ signaling. Journal of Alzheimer's Disease 27, 679-689.

Cherny, R.A., Atwood, C.S., Xilinas, M.E., Gray, D.N., Jones, W.D., McLean, C.A., Barnham, K.J., Volitakis, I., Fraser, F.W., Kim, Y., Huang, X., Goldstein, L.E., Moir, R.D., Lim, J.T., Beyreuther, K., Zheng, H., Tanzi R.E., Masters, C.L., Bush, A.I., 2001. Treatment with a copper-zinc chelator markedly and rapidly inhibits beta-amyloid accumulation in Alzheimer's disease transgenic mice. Neuron 30, 665-676.

Chua, B., Guo, K., Li, P., 2000. Direct cleavage by the calcium activated protease calpain can lead to inactivation of caspases. Journal of Biological Chemistry 275, 5131-5135.

Croall, D., Ersfeld, K., 2007. The calpains: modular designs and functional diversity. Genome Biology 8, 218.

Cukierman, T., Gerstein, H., Williason, J., 2005. Cognitive decline and dementia in diabetessystematic overview of prospective observational studies. Diabeteologia 48, 2460-2469. 
433

434

435

436

437

438

439

440

441

442

443

444

445

446

447

448

449

450

451

452

453

454

455

456

457

458

459

460

461

462

Das, A., Banik, N.L., Ray, S.K., 2006. Mechanism of apoptosis with the involvement of calpain and caspase cascades in human malignant neuroblastoma SH-SY5Y cells exposed to flavonoids. International Journal of Cancer 119, 2575-2585.

Dayem, A.A., Kim, B.W., Gurunathan, S., Choi, H.Y., Yang, G., Saha, S.K., Han, D., Han, J., Kim, K., Kim, JH., Cho, SG., 2014. Biologically synthesized silver nanoparticles induce neuronal differentiation of SH-SY5Y cells via modulation of reactive oxygen species, phosphatases, and kinase signaling pathways. Journal of Biotechnology 9, 934-943.

Ghoneim, M.M., El-Desoky, H.S., Abdel-Galeil, M.M., 2011. Electrochemistry of the antibacterial and antifungal drug nitroxoline and its determination in bulk form, pharmaceutical formulation and human blood. Bioelectrochemistry 80, 162-168.

Goll, D.E., Thompson, V.F., Li, H., Wei, W.E.L., Cong, J., 2003. The calpain system. Physiological Reviews 83, 731-801.

Haslinger, B., Mandl-Weber, S., Sellmayer, A., Lederer, S., Sitter, T., 2001. Effect of high glucose concentration on the synthesis of monocyte chemoattractant protein-1 in human peritoneal mesothelial cells: Involvement of Protein Kinase C. Nephron 87, 346-351.

Ho, F.M., Liu, S.H., Liau, C.S., Huang, P.J., Lin-Shiau, S.Y., 2000. High glucose-induced apoptosis in human endothelial cells is mediated by sequential activations of c-Jun NH2terminal kinase and caspase-3. Circulation 101, 2618-2624.

Igarashi, M., Wakasaki, H., Takahara, N., Ishii, H., Jiang, Z., Yamauchi, T., Kuboki, K., Meier, M., Rhodes, C., King, G., 1999. Glucose or diabetes activates p38 mitogen-activated protein kinase via different pathways. Journal of Clinical Investigation 103, 185-195.

Janson, J., Laedtke, T., Parisi, J., O'Brien, P., Peterson, R., 2004. Increased risk of type 2 diabetes in Alzheimer's disease. Diabetes 53, 474-481.

Kaur, D., Yantiri, F., Rajagopalan, S., Kumar, J., Mo, J., Boonplueang, R., Viswanath, V., Jacobs, R., Yang, L., Beal, M., DiMonte, D., Volitaskis, I., Ellerby, L., Cherny, R., Bush, A., Anderson, J., 2003. Genetic or pharmacological iron chelation prevents MPTP-induced neurotoxicity in vivo: A novel therapy for Parkinson's disease. Neuron 37, 899-909.

Kimura, C., Oike, M., Ito, Y., 1998. Acute glucose overload abolishes $\mathrm{Ca}^{2+}$ oscillation in cultured endothelial cells from bovine aorta: a possible role of superoxide anion. Circulation Research 82, 677-685. 
463

464

465

466

467

468

469

470

471

472

473

474

475

476

477

478

479

480

481

482

483

484

485

486

487

488

489

490

491

492

493

Kopf, D., Frolich, L., 2009. Risk of incident Alzheimer's disease in diabetic patients: a systemic review of prospective trials. Journal of Alzheimer's Disease 16, 677-685.

Kovalevich, J., Langford, D., 2013. Considerations for the use of SH-SY5Y neuroblastoma cells in neurobiology. Neuronal cell culture, Springer, 9-21.

Kumar, S., Kain, V., Sitasawad, S.L., 2012. High glucose-induced $\mathrm{Ca}^{2+}$ overload and oxidative stress contribute to apoptosis of cardiac cells through mitochondrial dependent and independent pathways. Biochimica et Biophysica Acta 1820, 907-920.

Lankiewicz, S., Luerjens, C.M., Bui, N.T., Krohn, A., Poppe, M., Cole, G., Saido, T., Prehn, J., 2000. Activation of calpain I converts excitotoxic neuronal death into a caspaseindependent cell death. Journal of Biological Chemistry 275, 17064-17071.

LeVine, H., Ding, Q., Walker, J.A., Voss, R.S., Augelli-Szafran, C.E., 2009. Clioquinol and other hydroxyquinoline derivatives inhibit $A \beta$ (1-42) oligomer assembly. Neuroscience Letters 465, 99-103.

Li, Y., Xu, S., Zhang, Q., Li, L., Lai, L., Zheng, T., Su, J., Yang, N., Li, Y., 2014.

Cytotoxicity study on SH-SY5Y cells cultured at high glucose levels and treated with bupivacaine. Molecular Medicine Reports 9, 515-520.

Li, Z., Zhang, W., Sima, A., 2003. C-peptide enhances insulin-mediated cell growth and protection against high glucose-induced apoptosis in SH-SY5Y cells. Diabetes/Metabolism Research and Reviews 19, 375-385.

Lin, H., Bhatia, R., Lal, R., 2003. Amyloid $\beta$ protein forms ion channels: implications for Alzheimer's disease pathophysiology. FASEB Journal 15, 2433-2444.

Maekawa, A., Lee, J., Nagaya, T., Kamiya, K., Yasui, K., Horiba, M., 2003. Overexpression of calpastatin by gene transfer prevents troponin I degradation and ameliorates contractile dysfunction in rat hearts subjected to ischemia/reperfusion. Journal of Molecular and Cellular Cardiology 35, 1277-1284.

Mahajan, V., Skeie, J., Bassuk, A., Fingert, J., Braun, T., Daggett, H., Folk, J., Sheffield, V., Stone, E., 2012. Calpain-5 mutations cause autoimmune uveitis, retinal neovascularization, and photoreceptor degeneration. PLoS Genetics 10, e1003001.

Mao, X., Schimmer, A., 2008. The toxicology of clioquinol. Toxicology Letters 182, 1-6.

McGinnis, K.M., Whitton, M.M., Gnegy, M.E., Wang, K.K.W., 1998. Calcium/Calmodulindependent protein kinase IV is cleaved by caspase-3 and calpain in SH-SY5Y human 
494

495

496

497

498

499

500

501

502

503

504

505

506

507

508

509

510

511

512

513

514

515

516

517

518

519

520

521

522

neuroblastoma cells undergoing apoptosis. Journal of Biological Chemistry 273, 19993 20000.

Newsholme, P., Haber, E., Hirabara, S., Rebelato, E., Procopio, J., Morgan, D., OliveiraEmilio, H., Carpinelli, A., Curi, R., 2007. Diabetes associated cell stress and dysfunction: role of mitodrial and non-mitochondrial ROS production and activity. Journal of Physiology $583,9-24$.

Ozdemir, S., Ugur, M., Gurdal, H., Turan, B., 2005. Treatment with AT(1) receptor blocker restores diabetes-induced alterations in intracellular $\mathrm{Ca}^{2+}$ transients and contractile function of rat myocardium. Archives Biochemistry and Biophysics 435, 166-174.

Piconi, L., Qualiaro, L., Assaloni, R., DA, R., Maier, A., Zuodar, G., Ceriello, A., 2006. Constant and intermittent high glucose enhances endothelial cell apoptosis through mitochondrial superoxide overproduction. Diabetes/Metabolism Research and Reviews 22.

Prachayasittikul, V., Prachayasittikul, S., Ruchirawat, S., Prachayasittikul, V., 2013. 8Hydroxyquinolines: a review of their metal chelating properties and medicinal applications. Drug Design, Development and Therapy 7, 1157-1178.

Rami, A., 2003. Ischemic neuronal death in the rat hippocampus: the calpain-calpastatin-caspase hypothesis. Neurobiology of disease 13, 75-88.

Raynaud, F., Marcilhac, A., 2006. Implication of calpain in neuronal apoptosis. A possible regulation of Alzheimer's disease. FEBS Journal 273, 3437-3443.

Scalia, R., Gong, Y., Berzins, B., Zhao, L., Sharma, K., 2007. Hyperglycemia is a major determinant of albumin permeability in diabetic microcirculation: the role of mu-calpain. Diabetes 56, 1842-1849.

Song, J., Kang, S., Kim, E., Kim, C.-H., Song, H.-T., Lee, J., 2015. Adiponectin receptormediated signaling ameliorates cerebral cell damage and regulates the neurogenesis of neural stem cells at high glucose concentrations: an in vivo and in vitro study. Cell Death and Disease 6, e1844.

Stockert, J.C., Blazques-Castro, A., Canete, M., Horobin, R.W., Villanueva, A., 2012. MTT assay for cell viability: intracellular localization of the formazan product is in lipid droplets. Acta Histochemica 114, 785-796. 
523 Suh, S., Jensen, K., Jensen, M., 2000. Histochemically reactive zinc in amyloid plaques,

524 angiopathy and degenerating neurons of Alzheimer's diseased brains. Brain Research 852, $525 \quad 274-278$.

526 Suwanjang, W., Abramov, A., Govitrapong, P., Chetsawang, B., 2013. Melatonin attenuates

527 dexamethasone toxicity-induced oxidative stress, calpain and caspase activation in human

528 neuroblastoma SH-SY5Y cells. Journal of Steroid Biochemistry and Molecular Biology 138, 529 116-122.

530 Suwanjang, W., Phansuwan-Pujito, P., Govitrapong, P., Chetsawang, B., 2012. Calpastatin 531 reduces calpain and caspase activation in methaphetamine-induced toxicity in human 532 neuroblastoma SH-SY5Y cultured cells. Neuroscience Letters 526, 49-53.

533 Todorovic, S., Jevtovic-Todorovic, V., 2014. Targeting of CaV3.2 T-type calcium channels in 534 peripheral sensory neurons for the treatment of painful diabetic neuropathy. Pflugers Archiv 535466.

536 Trombetta, M., Spiazzi, G., Zoppini, G., Muggeo, M., 2005. Review article: Type 2 diabetes 537 and chronic liver disease in the Verona diabetes study. Alimentary Pharmacology and 538 Therapeutics 2, 24-27.

539 Vosler, P., Brennan, C., Chen, J., 2008. Calpain-mediated signaling mechanisms in neuronal $540 \quad$ injury and neurodegeneration. Molecular Neurobiology 38, 78-100.

541 Wagenlehner, F.M.E., Münch, F., Pilatz, A., Bärmann, B., Weidner, W., Wagenlehner, 542 C.M., Straubinger, M., Blenk, H., Pfister, W., Kresken, M., Naber, K.G., 2014. Urinary 543 concentration and antibacterial activities of nitroxline at 250 milligrams versus trimethoprim 544 at 200 milligrams against uropathogens in healthy volunteers. Antimicrobial Agents and 545 Chemotherapy 58, 713-721.

546 Wilkins, S., Masters, C., Bush, A., Cherny, R., Finkelstein, D., 2009. Clioquinol protects 547 against cell death in Parkinson's disease models in vivo and in vitro. Advances in Behavioral 548 Biology 58, 431-442.

549 Wu, L., Nicholson, W., Knobel, S.M., Steffner, R.J., May, J.M., Piston, D.W., Powers, A.C., 550 2004. Oxidative stress is a mediator of glucose toxicity in insulin-secreting pancreatic islet 551 cell lines. Journal of Biological Chemistry 279, 12126-12134. 
552 Wuensch, T., Thilo, F., Krueger, K., Scholze, A., Ristow, M., Tepel, M., 2010. High glucose-

553 induced oxidative stress increases transient receptor potential channel expression in human

554 monocytes. Diabetes 59, 844-849.

555

556 


\section{Figure 1 (on next page)}

8-Hydroxyquinoline, clioquinol and nitroxoline.

8-Hydroxyquinoline, clioquinol and nitroxoline. A, Chemical structures. B, Effect of 8hydroxyquinoline and derivatives on cell viability in SH-SY5Y cells. Cells were treated with 8hydroxyquinoline and derivatives at 1 and $10 \mu \mathrm{M}$ for $24 \mathrm{hr}$. Cell viability was measured using the MTT assay and is presented as the percentage of control cells. The results are expressed as the mean \pm S.E.M. of four independent experiments. One-way analysis of variance (ANOVA) and the Tukey-Kramer multiple comparisons test were performed for statistical analysis. ${ }^{* * P} P<0.01$ and $* * * P<0.001$ compared with the control. 
Fig. 1.

A<smiles>Oc1cccc2cccnc12</smiles>

$\mathrm{OH}$

8-Hydroxyquinoline

B

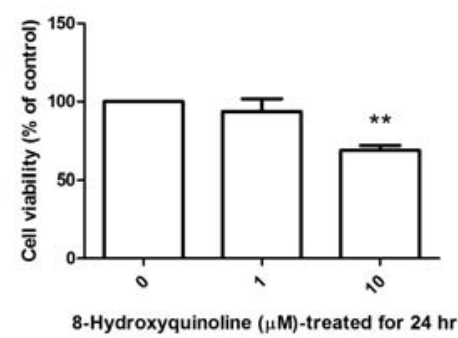

Clioquinol<smiles>Oc1c(I)cc(Cl)c2cccnc12</smiles>

$\mathrm{OH}$

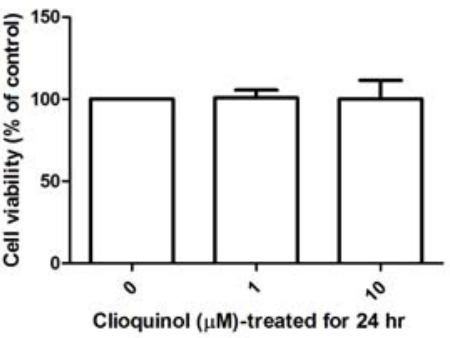<smiles>O=[N+]([O-])c1ccc(O)c2ncccc12</smiles>

Nitroxoline

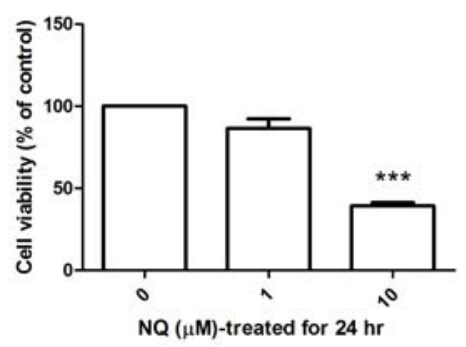




\section{Figure 2 (on next page)}

High glucose-induced alteration of cell viability, capain and capastatin proteins expression.

Cells treated with D-glucose concentrations (30,60 and $120 \mathrm{mM}$ ) for $2 \mathrm{hr}$ and $24 \mathrm{hr}$ were compared to cells treated with control medium containing $5.5 \mathrm{mM}$ D-glucose and mannitol as an osmotic control. A, Cell viability was measured using the MTT assay. B, The levels of calpain and calpastatin were determined by Western blot analysis. Protein bands were quantified by densitometry, and their differences are represented in the graph as the ratio of calpain and calpastatin to $\beta$-actin. The results are expressed as the mean + S.E.M. of four independent experiments. One-way analysis of variance (ANOVA) and Tukey-Kramer multiple comparisons test were performed for statistical analysis, $* P<0.05, * * P<0.01$ and $* * * P<0.001$

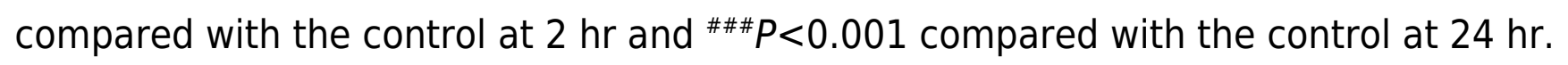


Fig. 2.

A

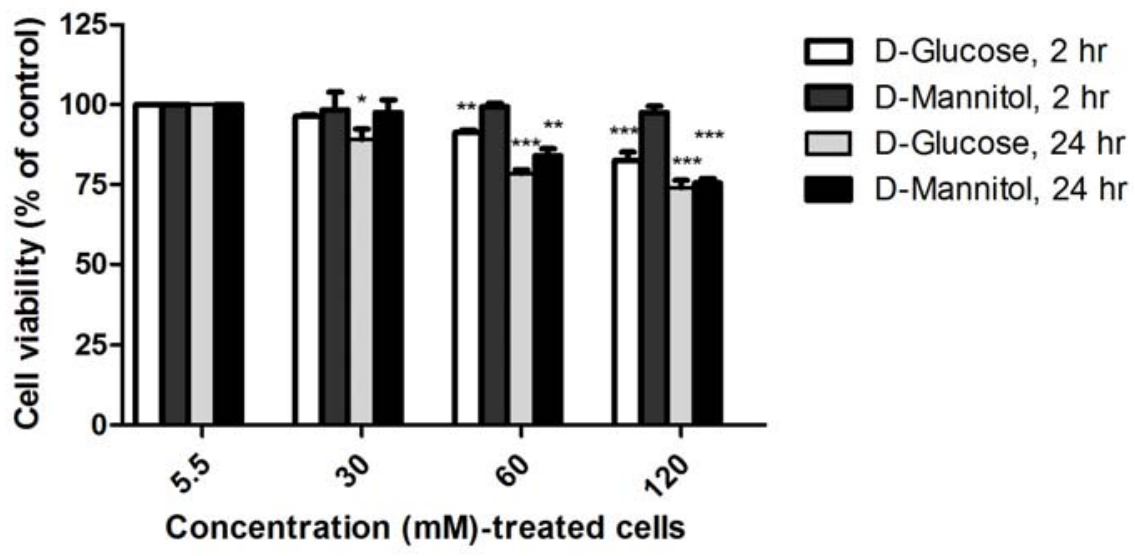

B
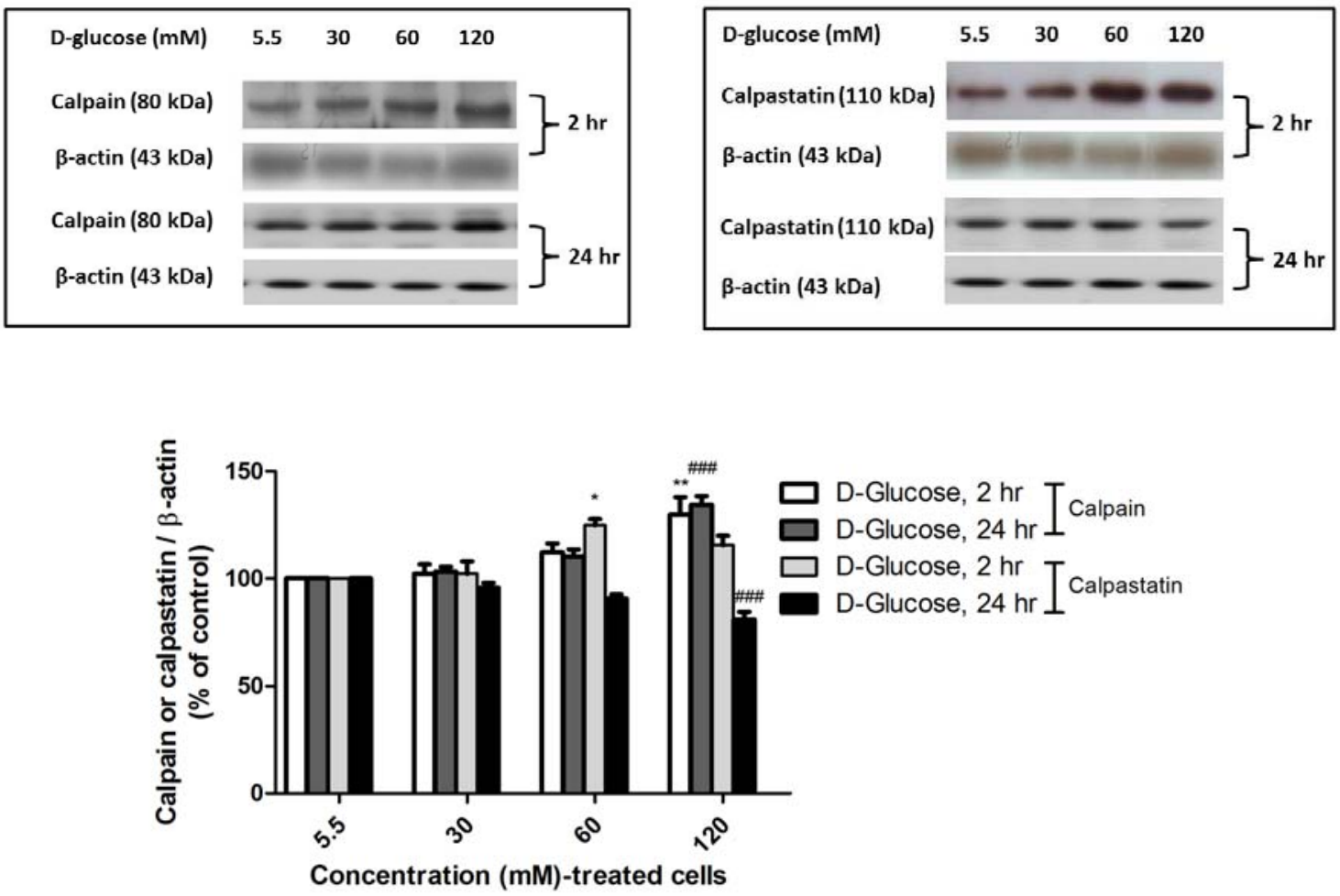


\section{Figure 3 (on next page)}

Imaging microscopic analysis of SH-SY5Y cells demonstrating the D-glucose-induced increase in calpain expression.

Cells were treated with $120 \mathrm{mM} \mathrm{D-glucose}$ for $24 \mathrm{hr}$. The control cells were incubated with the culture medium for $24 \mathrm{hr}$. The green color indicates calpain immunostaining using fluorescein-5-isothiocyanate (FITC)-conjugated anti-IgG. 
Fig. 3.
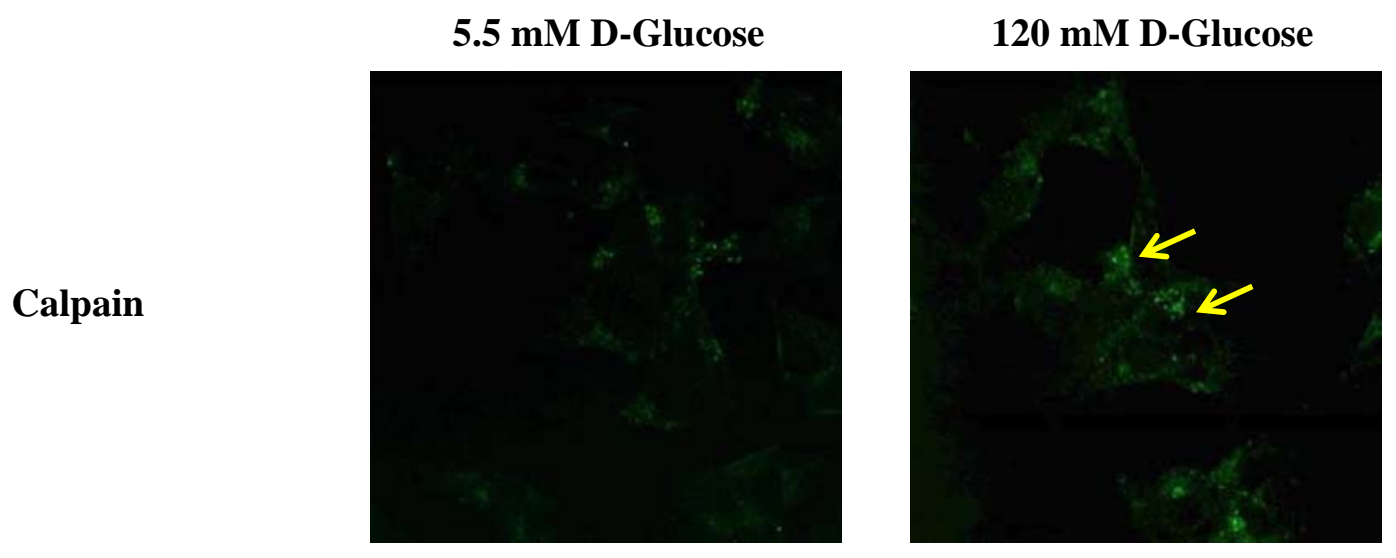

MitoTracker Red
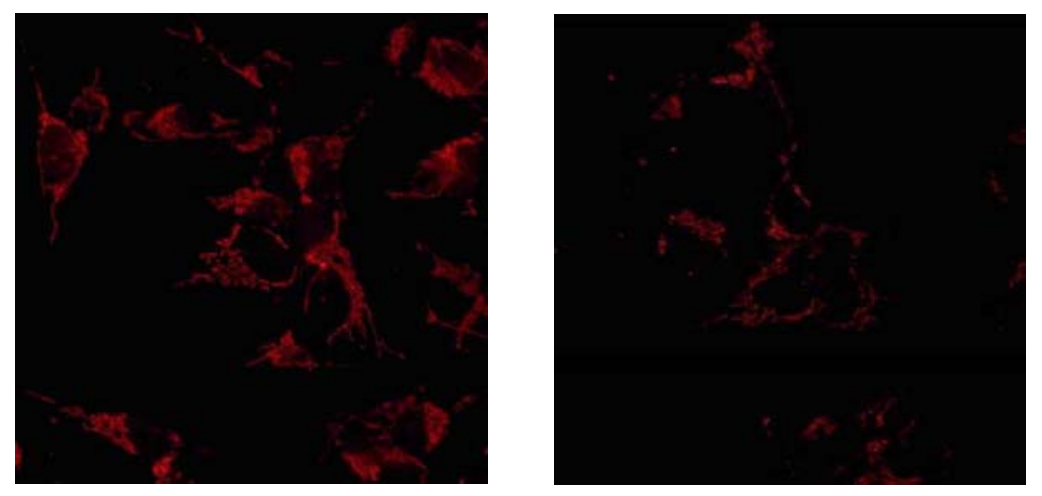

\section{Merge}
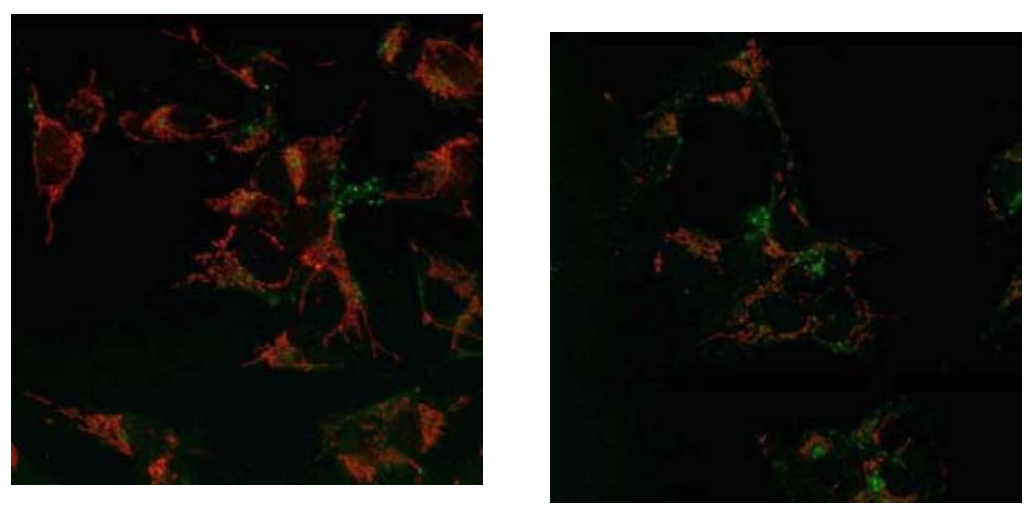

Phase contrast
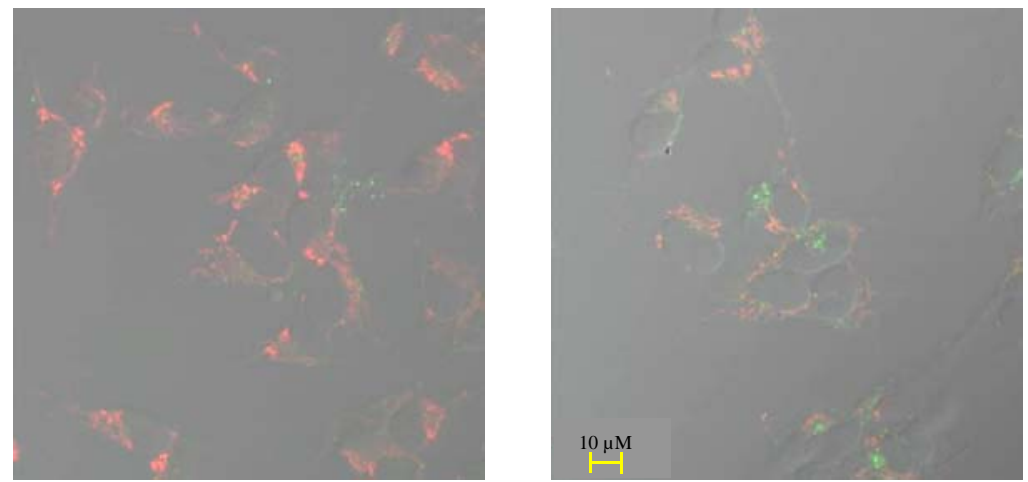


\section{Figure 4 (on next page)}

The effect of 8-hydroxyquinoline and derivatives on the high glucose (120 mM) in SHSY5Y cells.

Cells were treated with high glucose for $24 \mathrm{~h}$. Some cells were pre-treated with $1 \mu \mathrm{M} 8$ hydroxyquinoline and derivatives for $2 \mathrm{~h}$ prior to incubation with $120 \mathrm{mM}$ high glucose for another $24 \mathrm{~h}$. The control cells were incubated with the culture medium for $24 \mathrm{~h}$. A, Cell viability was measured using the MTT assay. The results are expressed as the mean \pm S.E.M. of four independent experiments. B, Calpain and C, calpastatin expressions were determined by Western blot analysis. Protein bands were quantified by densitometry, and the changes are represented in the graph. Calpain and calpastatin expressions are presented as the ratios of calpain or calpastatin / $\beta$-actin protein bands. The results are expressed as the mean \pm S.E.M. of three independent experiments. One-way analysis of variance (ANOVA) and the Tukey-Kramer multiple comparisons test were performed for statistical analysis. $* P<0.05$, ${ }^{*} P<<0.01$ and ${ }^{* * *} P<0.001$ compared with the control and ${ }^{*} P<0.05,{ }^{* \#} P<0.01,{ }^{\# \# *} P<0.001$ compared with high glucose-treated cells. 
Fig. 4.

A

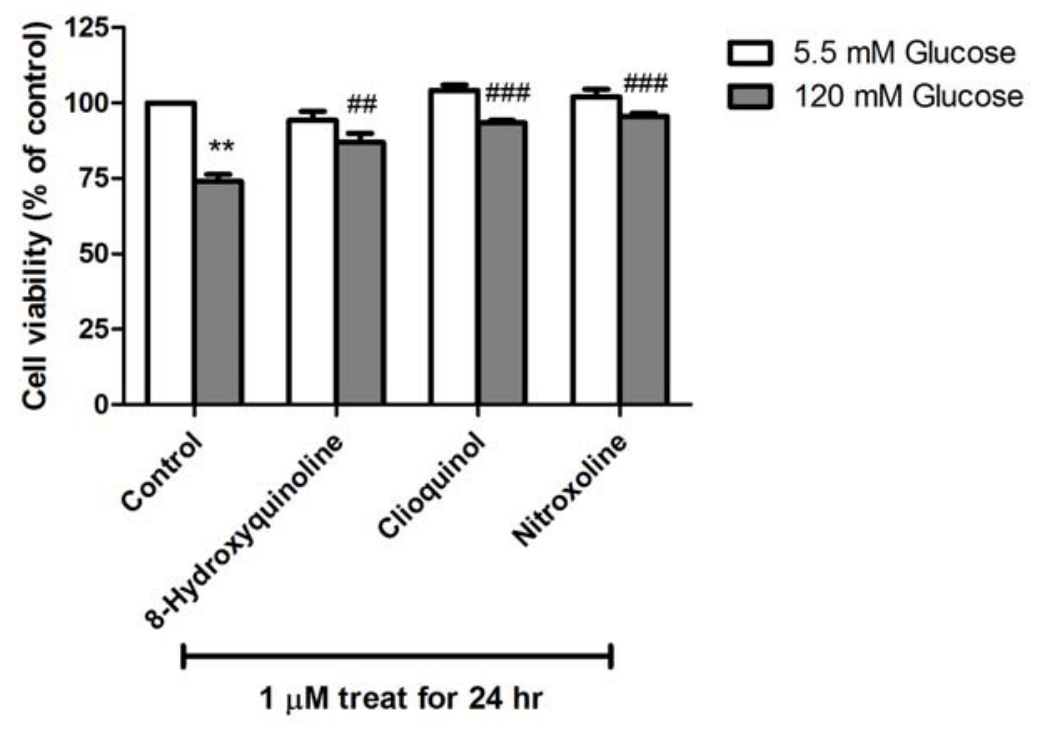

B

C

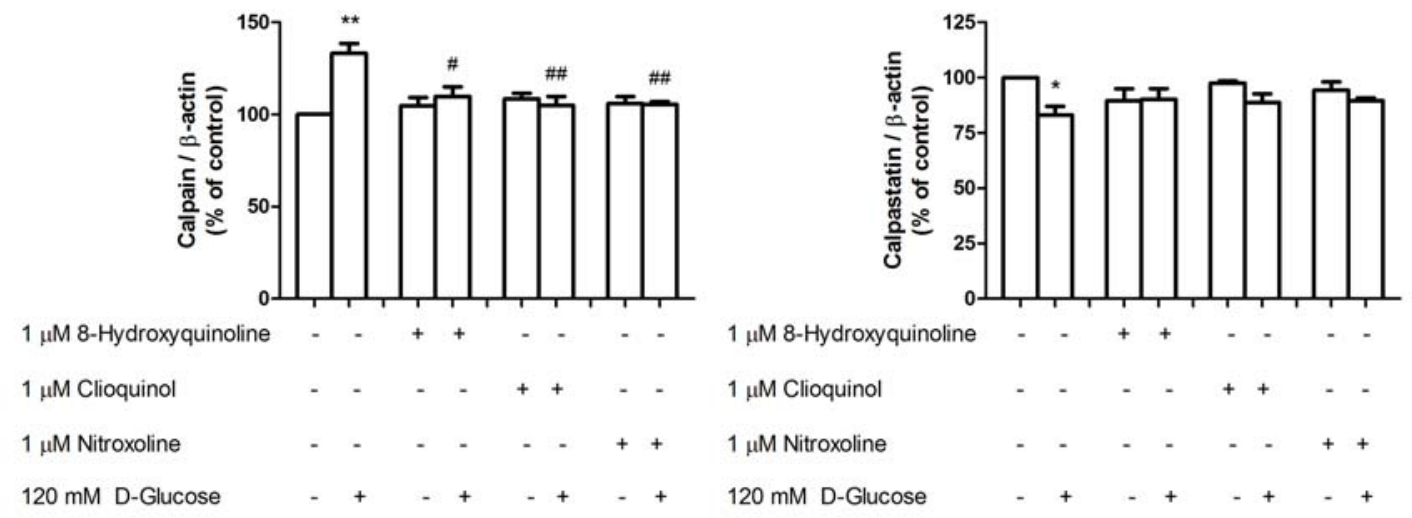

